\title{
Levantamento sobre o uso de drogas por estudantes do ensino médio: Uma revisáo sistemática ${ }^{1}$
}

\author{
Clamarta Pasuch $^{\mathrm{a}}$, Margareth da Silva Oliveira ${ }^{\mathrm{b}}$ \\ aPontifícia Universidade Católica do Rio Grande do Sul - PUCRS, Porto Alegre, RS, Brasil \\ bPrograma de Pós-graduação em Psicologia, Faculdade de Psicologia, Pontifícia Universidade Católica do Rio \\ Grande do Sul - PUCRS, Porto Alegre, RS, Brasil
}

\begin{abstract}
Resumo: As primeiras experiências com drogas ocorrem frequentemente na adolescência, em ambientes familiares com substâncias lícitas como álcool e tabaco, e os dados indicam que a adolescência é uma fase de exposição e vulnerabilidade ao consumo de substâncias. Objetivo: Conhecer a prevalência do uso de drogas entre estudantes do ensino médio. Método: Revisão sistemática de literatura. Resultados: Foram localizados 184 artigos e, conforme os critérios de exclusão, 13 artigos foram adotados, sendo 3 que abordam o tema na região Sul, 1 na região Nordeste, 1 na região Norte e 8 na região Sudeste do Brasil. Discussão: Dos 13 artigos examinados, viu-se crescimento no uso de drogas entre adolescentes escolares. A pesquisa revela aumento significativo de uso na vida, uso frequente e uso pesado de várias drogas. Verificou-se que os estudantes apresentam contato precoce com substâncias psicoativas, fazendo uso em grande quantidade, sejam lícitas como álcool e tabaco, ou ilícitas, como solventes e maconha. A variável mais importante relatada para esse comportamento foi a curiosidade. Conclusão: Há o aumento no uso de substâncias entre estudantes e a abordagem do tema nas escolas é a melhor maneira de prevenir.
\end{abstract}

Palavras-chave: Drogas, Adolescentes, Estudantes, Ensino Médio.

\section{Survey on drug use among high school students: A systematic review}

\begin{abstract}
The first experiments with drugs often occur in adolescence, in familiar surroundings, with legal substances such as alcohol and tobacco. Data indicate that adolescence is a phase of exposure and vulnerability to substance use. Objective: To determine the prevalence of drug use among high school students. Method: Systematic review. Results: We found 184 articles, and according to the exclusion criteria, 13 articles were adopted: 3 that address the theme in the South, one in the Northeast, one in the North, and the 8 in the Southeastern Brazilian regions. Discussion: We noticed a growth in drug use among adolescent students in the 13 articles examined. Research reveals significant increase in lifetime use, frequent use and heavy use of various drugs. We found that students have early contact with psychoactive substances, using them in large quantities, whether legal such as alcohol and tobacco, or illicit drugs like marijuana and solvents. The most important variable for this behavior was curiosity. Conclusion: There is an increase in substance use among high school students. Approaching the subject in schools is the best way to prevent drug use.
\end{abstract}

Keywords: Drugs, Teenagers, Students, High School.

Autor para correspondência: Clamarta Pasuch, Faculdade de Psicologia, Pontifícia Universidade Católica do Rio Grande do Sul, Avenida Ipiranga, 6681, prédio 11, CEP 90619-900, Porto Alegre, RS, Brasil, e-mail clamarta.pasuch@acad.pucrs.br

Recebido em 13/8/2013; $1^{\text {a }}$ Revisão em 13/11/2013; $2^{a}$ Revisão: 12/3/2014; Aceito em 19/3/2014 


\section{Introdução}

A dependência química é cada vez mais um desafio para pais, profissionais da saúde, educadores, gerenciadores de políticas públicas, legisladores, enfim, para toda a comunidade. O impacto para a sociedade, para a economia e para a saúde decorrente desse transtorno é imenso. Nas últimas décadas, a experimentaçáo de drogas tem sido cada vez mais precoce, com quadros de abuso e dependência, apesar dos esforços preventivos estarem aumentando (DIEHL; CORDEIRO; LARANJEIRA, 2011).

Ao observar a história da humanidade, nota-se que o homem sempre conviveu com o consumo de drogas sem que isto fosse motivo de alarde social. Os seres humanos buscaram o prazer, o alívio da ansiedade e outras alteraçốes do nível de consciência por meio da ingestão de várias substâncias naturais ou sintéticas (COLASSANTI et al., 1996 apud SANCEVERINO; ABREU, 2004). Consumir drogas é uma prática humana, milenar e universal, assim, a maioria dos grupos sociais tem convivido com diversas substâncias psicoativas ao longo do tempo.

$\mathrm{O}$ uso de substâncias psicoativas tornou-se motivo de preocupaçáo a partir dos anos 1960, a ponto de ser considerado um problema de saúde pública devido ao crescente consumo, principalmente entre os jovens, pelos riscos que oferecem à saúde, além dos problemas sociais associados ao uso dessas substâncias (BUCHER, 1992 apud DEZONTINE et al., 2007).

Para a Organização Mundial da Saúde (OMS), "[...] droga é qualquer substância natural ou sintética que, administrada por qualquer via no organismo, afeta sua estrutura ou funçâo [...]", e a pessoa com menor possibilidade de usar a droga é aquela que é bem informada, bem integrada na família e sociedade, com boa saúde e qualidade de vida satisfatória e com difícil acesso às drogas (SANCEVERINO; ABREU, 2004, p. 1048).

A adolescência é uma fase da vida do ser humano caracterizada por mudanças biológicas, cognitivas, emocionais e sociais, constituindo-se um importante momento para a adoção de novas práticas, comportamentos e ganho de autonomia. É um período marcado pela indecisão, sinalizando a passagem da infância protegida para a exposição à vida adulta, e a tendência grupal com a evoluçáo da sexualidade também são aspectos importantes. Nessa fase, estimulado pelas intensas transformaçôes, o adolescente torna-se mais vulnerável, o que pode fragilizar sua saúde, com alimentação inadequada, sedentarismo, tabagismo, consumo de álcool e outras drogas (VIEIRA et al., 2008).
De acordo com Pinsky e Bessa (2004), o potencial de abuso de drogas está relacionado ao fato de elas, inicialmente, produzirem uma sensação agradável de bem-estar. Isso se deve à ação direta ou indireta sobre uma via neuronal cerebral responsável pela capacidade de sentir prazer/satisfação em diferentes situaçôes; essa via é também conhecida como via do reforço, da gratificação ou do prazer. Com o uso repetitivo da droga, a sensação agradável diminui e o indivíduo, por consequência, se sente obrigado a aumentar a quantidade de uso da droga para voltar a desfrutar daquele bem-estar inicial, e assim inicia-se a dependência.

As primeiras experiências com drogas ocorrem frequentemente na adolescência. Nessa fase, o indivíduo é particularmente vulnerável do ponto de vista psicológico e social (SOLDERA et al., 2004). Essa é uma fase de procura e de conflitos, na qual os adolescentes dão muita importância aos seus grupos, seus relacionamentos, e entram em conflito consigo mesmos e com a família; isso os torna mais vulneráveis a situaçóes externas, tais como o consumo de drogas, delinquência e condutas de risco. Nas últimas décadas, o fenômeno da drogadição alcançou extraordinária importância por sua difusão, consequências sociais e sanitárias. Esse fato se evidencia pela evolução que existe nas diversas culturas com crescente desenvolvimento de uma sociedade industrial e de consumo, privilegiando o uso dessas substâncias como forma de favorecer a socialização e o bem-estar (JINEZ; SOUZA; PILLON, 2009).

Segundo Schenker e Minayo (2005), a família tem o papel de inserir seus membros na cultura e ser instituidora das relaçóes primárias, bem como influenciar a forma como o adolescente reage à ampla oferta de droga na sociedade atual. Relaçôes familiares saudáveis, desde o nascimento da criança, servem como fator de proteçáo para toda a vida e, de forma muito particular, para o adolescente. No entanto, problemas enfrentados na adolescência, plantados na infância, têm um contexto de realizaçáo muito mais ampliado. Essa etapa constitui um período crucial no ciclo vital para o início do uso de drogas, seja como mera experimentação seja como consumo ocasional, indevido ou abusivo.

O uso de drogas, para alguns, faz parte do processo normal de busca de novas experiências, $d a$ busca de individualização e do amadurecimento que caracteriza essa fase e, por isso, nem todos se tornam dependentes. Contudo, a dependência é um risco que o jovem corre ao usar essas substâncias. Além de que, por ser uma fase de importante transformação e maturação do sistema nervoso central, o uso de drogas 
nesse período pode prejudicar o desenvolvimento e causar danos ao potencial intelectual, emocional e social. Por isso, a família e a escola sáo importantes estruturas que devem ficar atentas e dar orientaçóes, apoio e sólidas referências emocionais, intelectuais e de valores (DIEHL; CORDEIRO; LARANJEIRA, 2011).

Portanto, considerando essa problemática entre adolescentes, o presente estudo tem por objetivo verificar a prevalência do uso de drogas entre estudantes do ensino médio a partir de comparaçôes entre regióes do país.

A questão do consumo de substâncias psicoativas entre adolescentes tem mobilizado profissionais de diversas áreas e de vários segmentos da sociedade, na busca de identificar padrôes de seu uso e fatores associados ao consumo para encontrar medidas que o reduzam entre os adolescentes. Assim, esse estudo justifica-se em conhecer o consumo de drogas entre escolares para que as políticas públicas e a instituição escolar possam auxiliar na prevenção e tratamento tanto de drogas lícitas como ilícitas.

\section{Método}

Por se tratar de uma pesquisa de revisão sistemática, foram consultadas as seguintes bases de dados: "Pesquisa Múltipla" disponibilizada para alunos e professores da Pontifícia Universidade Católica do Rio Grande do Sul (PUCRS). Essa ferramenta facilita o processo de consulta, pois abrange várias bases de dados importantes como o Catálogo On-Line da PUCRS, PubMed/Medline, Lilacs. Além disso, foram utilizadas as ferramentas SciELO e Google Acadêmico.

Foram analisadas publicações de artigos em língua portuguesa, entre 2002 e 2012, que avaliam a prevalência do uso de drogas entre escolares do ensino médio nos estados brasileiros. Nas bases de dados, foram pesquisados os artigos que apresentassem os seguintes descritores: "drogas", "adolescência", "estudantes", "ensino médio".

A busca com os descritores citados resultou em 184 artigos, em que 68 estavam duplicados e 22 o ano de publicação era inferior a 2002, portanto, foram excluídos. Ficaram 94 resumos de artigos em que foi realizada a leitura e feita a seleção a partir dos seguintes critérios de inclusão: (a) abordar o uso de drogas; (b) a população ser de adolescentes; (c) serem estudantes do ensino médio; (d) conter informaçôes dos últimos 10 anos. Foram excluídos os resumos de revisão sistemática, sem dados de pesquisa epidemiológica, com dados do ensino fundamental e os que não eram de amostra brasileira.

\section{Resultados e discussão}

Dos 94 resumos, foram encontrados 13 artigos que preencheram os critérios adotados e constituíram a versão final dessa busca. Os dados foram separados por regióes geográficas do Brasil para melhor visualização e comparação dos dados.

Conforme os dados citados na Tabela 1, as drogas que se destacam são o álcool e o tabaco, seguidas dos inalantes e maconha.

Ao comparar os dados coletados dessa pesquisa sistemática com os dados de Carlini et al. (2005), no II Levantamento Domiciliar sobre o Uso de Drogas Psicotrópicas no Brasil, um estudo envolvendo as 108 maiores cidades do país, realizado pelo CEBRID - Centro Brasileiro de Informaçôes sobre Drogas Psicotrópicas, percebe-se que o padrão de consumo é semelhante e as drogas usadas também, como mostra a tabela. Alguns dados parecem indicar que o uso de drogas ilícitas, álcool e tabaco, varia segundo o sexo e a idade na populaçáo de adolescentes na cidade de Pelotas. As meninas estáo fumando mais que os meninos e estes consomem mais álcool que as meninas e parecem fazer uso continuado de drogas ilícitas e em maior percentual. Questôes como classe social, escolaridade, vínculo com a escola e a ocorrência de reprovaçóes escolares estiveram mais associadas ao consumo de tabaco e drogas ilícitas, estando o consumo ilícito intimamente associado ao prejuízo no desempenho escolar e na permanência na escola (HORTA et al., 2007).

O álcool e o tabaco foram as drogas mais utilizadas pelos estudantes. Os dados obtidos no município de Palhoça, SC, são superiores ao estudo realizado por Souza e Martins na cidade de Cuiabá, MT, com índices de 78,6\% para o álcool e 29,0\% para o tabaco. Foram semelhantes aos obtidos em levantamento realizado na cidade de Ribeirão Preto, SP, em 1997 que apresentou índice de 88,9\% para o álcool e $37,7 \%$ para o tabaco (SANCEVERINO; ABREU, 2004). É curioso notar que muitos dos pesquisados informaram que já haviam utilizado algum tipo de droga, exceto álcool e tabaco, uma vez na vida.

No estudo realizado em Palhoça, percebe-se um número maior de usuários de álcool, enquanto o de usuários de tabaco se faz de maneira semelhante entre as capitais e o município. Os solventes são os mais consumidos depois do álcool e tabaco. Em seguida temos as anfetaminas, que, segundo o estudo, a prevalência pode ter relação com o uso de 


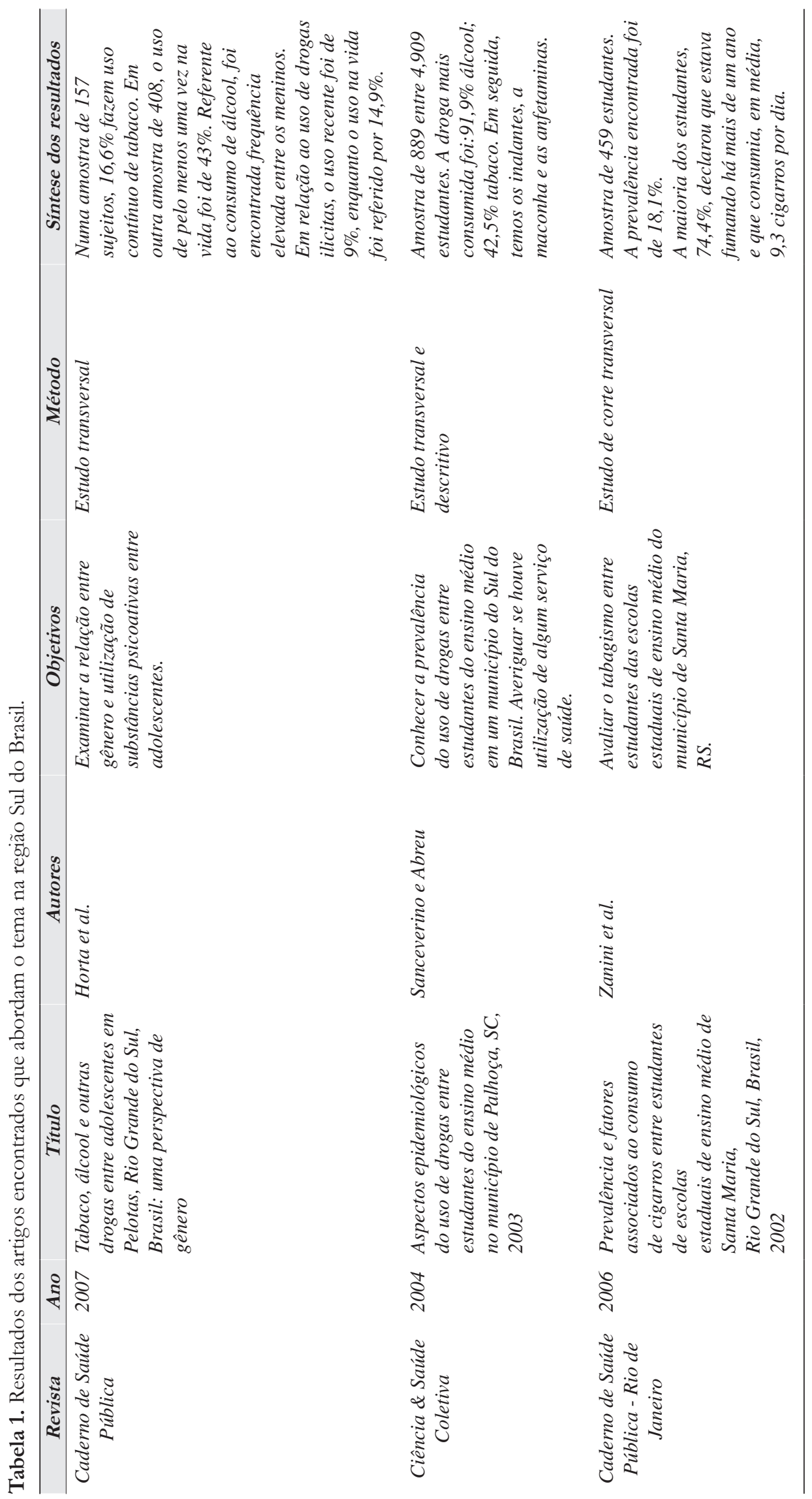


remédios para emagrecimento (SANCEVERINO; ABREU, 2004).

Conforme Zanini et al. (2006), no Rio Grande do Sul, em 1995, 27,7\% da populaçấo com 15 anos ou mais de idade eram fumantes regulares. O uso de tabaco é bastante precoce na vida dos estudantes, sendo que, entre os 10 e 12 anos de idade, cerca de $11,6 \%$ já fizeram, pelo menos, uso experimental do cigarro. $\mathrm{O}$ autor refere que, a cada ano, aproximadamente 100 mil adolescentes começam a fumar, 80\% são de países em desenvolvimento.

O estudo realizado em Santa Maria aponta a prevalência de tabagismo entre os estudantes (18\%) e condiz com o estudo de Barbosa et al. (1989), que observaram um consumo de $19,5 \%$ entre estudantes das dez capitais brasileiras, exceto Porto Alegre (35,3\%) de 2002 a 2003 (ZANINI et al., 2006).

No Rio Grande do Sul, as autoridades da área da saúde devem procurar urgentemente intervir com programas antitabagismo, considerando que, em Porto Alegre, encontram-se as maiores proporções de fumantes, tanto no sexo masculino $(28,2 \%)$ quanto feminino $(22,9 \%)$.

Nas últimas décadas, tem-se verificado uma preocupação marcante de vários setores nacionais, no sentido de embasamento científico sobre o consumo de cigarros entre os estudantes das escolas brasileiras, já que, segundo o CEBRID, 6\% dos adolescentes consomem cigarros frequentemente.

Segundo Zanini et al. (2006), o fumo é fator causal de cinquenta doenças diferentes, sendo diretamente responsável por $30 \%$ das mortes por câncer, $90 \%$ por câncer pulmonar, além das doenças coronarianas e cerebrovasculares. Outras doenças também estão relacionadas ao uso do tabaco, como aneurisma arterial, trombose vascular, úlcera do aparelho digestivo, infecçôes respiratórias e impotência sexual no homem.

A regiāo Sudeste apresenta dados significativos (conforme a Tabela 2) e que requerem atenção especial, principalmente as áreas da saúde que estão em busca de melhores estratégias de ação.

A Tabela 2 aponta os estudos realizados na região Sudeste do país. É nítido que houve mais pesquisas nesses estados que nos demais. Sem dúvida, o álcool e o tabaco são as drogas mais consumidas, seguidas pelos solventes e maconha. Segundo Carlini et al. (2005), o II Levantamento Domiciliar realizado pelo CEBRID também aponta dados nas mesmas proporçóes da Tabela 2.

O álcool aparece em primeiro lugar e bem à frente do segundo colocado, apresentando taxas elevadas e isso se revela em diversas pesquisas na regiáo; o consumo do álcool apresenta ampla aceitação social e é inclusive incentivado. Os pais preocupam-se com as drogas, como a maconha e a cocaína, e se esquecem do álcool que pode trazer grandes danos à saúde e bem-estar do adolescente, podendo comprometer toda a vida.

O uso de solventes também aumentou significativamente, comparado a pesquisas de anos anteriores. Em países da América Latina, os estudos epidemiológicos revelam que, excluindo o tabaco e o álcool, os solventes são as drogas mais consumidas. Já nos Estados Unidos, a maconha é a droga mais usada e os solventes ocupam o terceiro lugar entre os estudantes (ZENAIDE; BALDACCI, 2006). Conforme Pinsky e Bessa (2004), o uso de solventes ocorre em diversas partes do mundo, principalmente por crianças e adolescentes de países subdesenvolvidos ou por populaçôes socioeconomicamente marginalizadas; isso se deve ao valor econômico da droga e por ser uma substância presente em muitos produtos de uso doméstico. As altas prevalências encontradas indicam que o uso dessas drogas é preocupante e deve ser tomado em conta em relação a possíveis açôes educativas, preventivas e terapêuticas para jovens estudantes.

Os dados obtidos na pesquisa realizada nas escolas de Assis, SP são semelhantes aos encontrados pelos pesquisadores do CEBRID para a cidade de São Paulo, porém um pouco inferior aos de outras capitais do país.

Uma das características encontradas entre os estudantes que fazem uso de bebida alcoólica é possuir um familiar que faz uso excessivo de álcool. Um estudo realizado com colegiais e universitários em uma cidade do interior do estado de São Paulo, com aproximadamente 18 mil habitantes, aponta que aproximadamente $30 \%$ dos estudantes que bebem possui algum parente com problemas relacionados à bebida (MARTINS et al., 2008). Esses dados foram encontrados como preditores entre outros estudos.

Por meio de estudos realizados em várias cidades brasileiras, observou-se que $68 \%$ da populaçáo pesquisada, com indivíduos de várias faixas etárias, usou álcool em algum momento da vida ou frequentemente. Essa supremacia é preocupante e indica que devem ser tomadas medidas eficazes para conter sua utilização (DEZONTINE et al., 2007).

A pesquisa realizada no município de São José do Rio Preto mostra uma situação inquietante. Apesar do consumo de álcool e tabaco apresentar índices semelhantes a outras localidades e estar na média brasileira, o consumo de drogas ilícitas, 


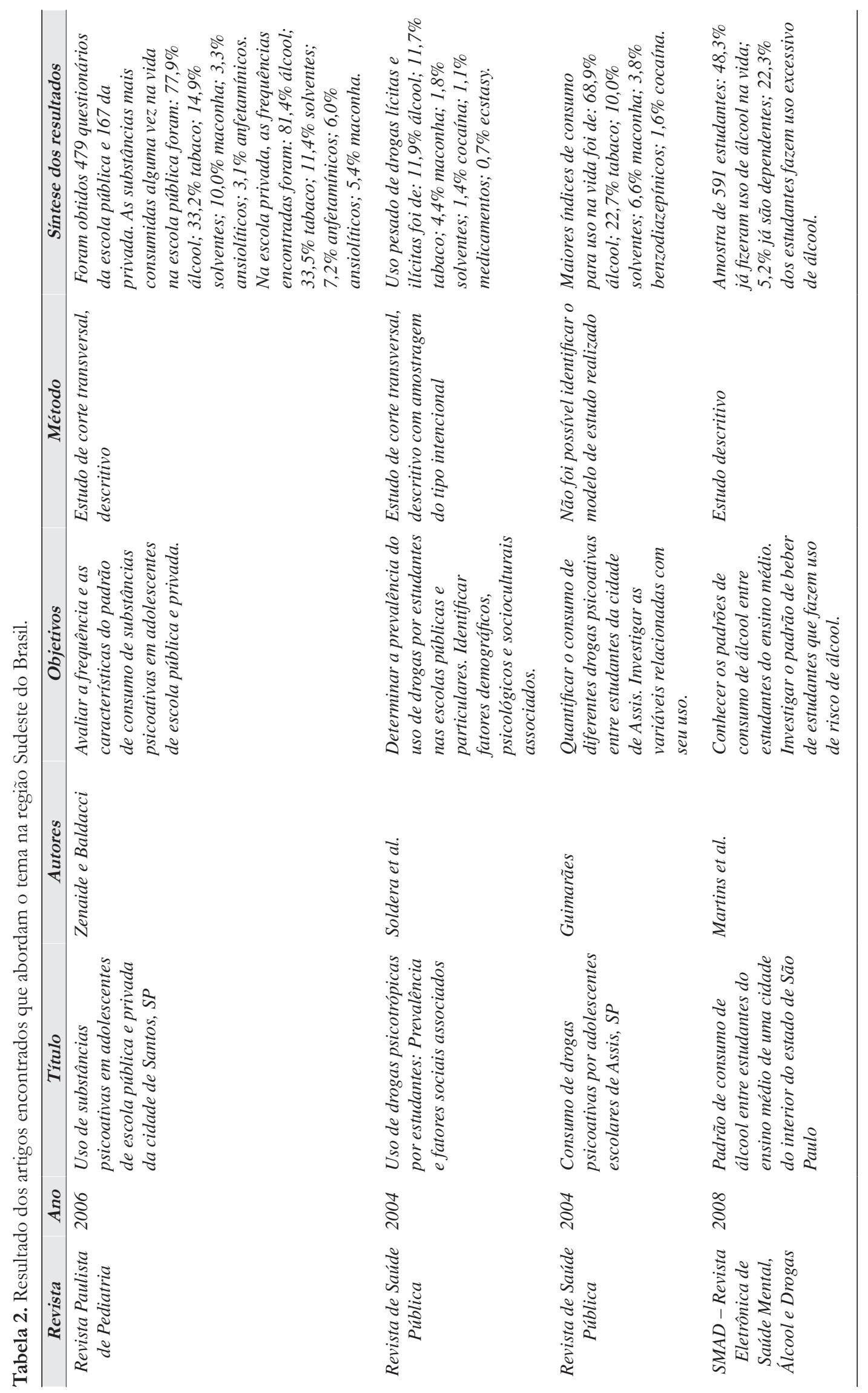




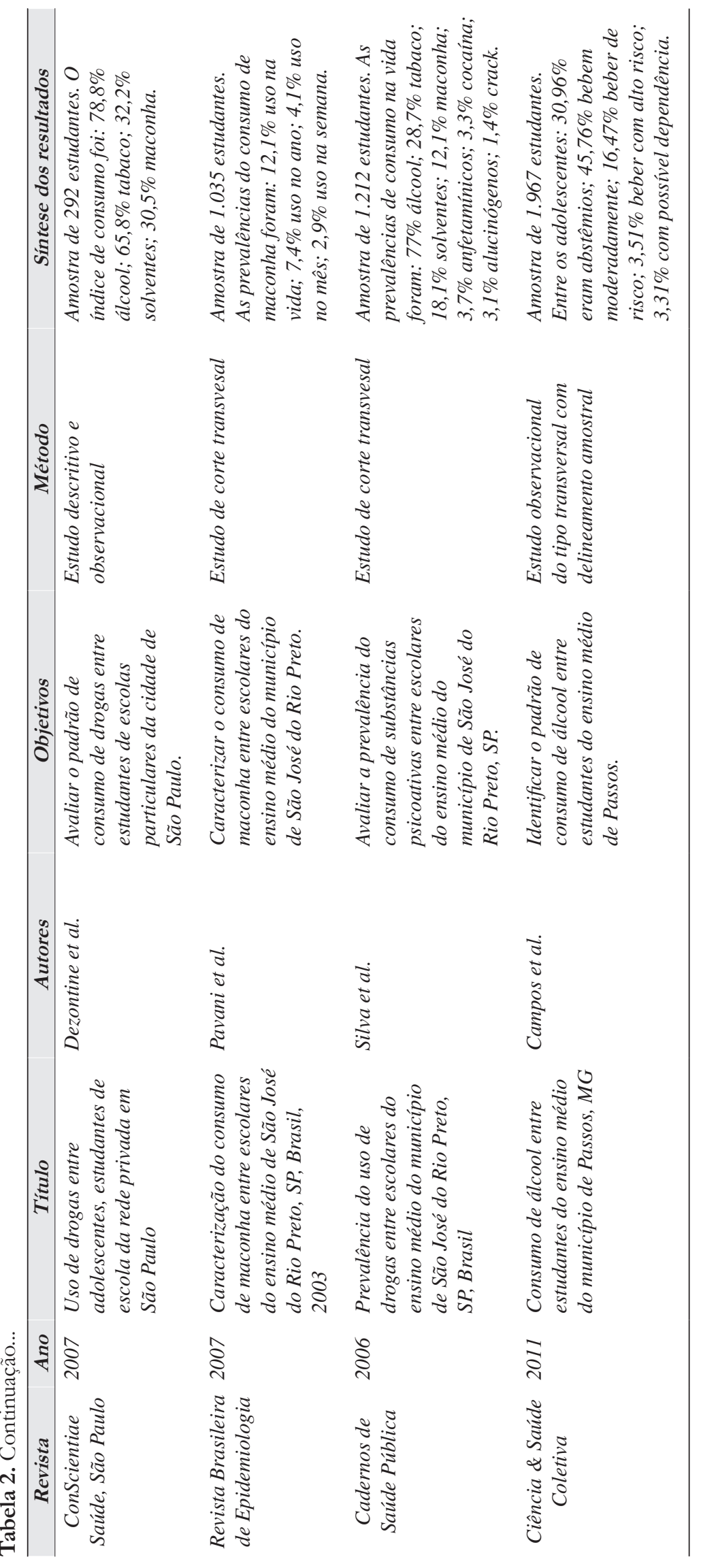


como a maconha, é superior ao encontrado em outros estudos no Brasil em geral, assemelhando-se somente à condição encontrada em Pelotas no Rio Grande do Sul (SILVA et al., 2006).

Para Pinsky e Bessa (2004), a maconha é a droga mais usada no Brasil, entre as drogas ilícitas. No levantamento de $1997,7,6 \%$ dos estudantes relataram já ter experimentado maconha ao menos uma vez. As capitais que apresentaram maior consumo estavam situadas na regiáo Sul com 11,9\%, em Curitiba e 14,4\%, em Porto Alegre. Esses dados se assemelham aos que constam nesse estudo, pois a maconha e os solventes estão entre as drogas ilícitas mais consumidas.

O estudo feito em Passos, com estudantes do ensino médio, revela o consumo de grande quantidade de bebida alcoólica em uma única ocasião (CAMPOS et al., 2011). Pesquisas alertam que esse tipo de comportamento traz grandes consequências ao indivíduo, como intoxicação e predisposição à continuidade do uso na vida adulta. Nessa mesma pesquisa, realizada por Campos et al. (2011), os participantes revelam que não foram capazes de controlar a quantidade de bebida a ser ingerida e que não conseguiram cumprir compromissos em função do consumo desta. Outro dado que merece destaque é o de $10,34 \%$ dos estudantes afirmarem já ter ingerido pela manhã para se sentir melhor. $\mathrm{O}$ sentimento de culpa depois do consumo é grande, chegando a 19,98\% dos entrevistados. Também $4,83 \%$ relataram ter se prejudicado ou prejudicado outra pessoa, devido à bebida.
Dezontine et al. (2007) referem que a ingestáo de álcool está associada com eventos de violência, sendo responsável por vários casos de agressão atendidos em hospitais, assim como acidentes de carro. Além disso, o consumo de álcool estimula a atividade sexual entre os adolescentes, uma vez que, logo após o uso de álcool, a libido aumenta e o desempenho sexual melhora, sendo esse um dos fatores que estimulam o uso dessa substância entre os jovens.

Anualmente, 1,7 milhão de adolescentes no mundo perdem a vida, a maioria por acidente de trânsito, suicídio e homicídio, muitas vezes associados ao uso de álcool e outras drogas (VIEIRA et al., 2008).

$\mathrm{Na}$ região Nordeste do Brasil, identificou-se apenas um estudo, conforme a Tabela 3 .

O estudo realizado na regiáo metropolitana do Recife sobre o uso de álcool entre estudantes mostra que $29,8 \%$ dos entrevistados relataram ter consumido álcool nos 30 dias que antecederam a pesquisa, chegando até a embriaguez, reforçando o que mostra a Tabela 3.

Conforme Carlini et al. (2005), o II Levantamento Domiciliar sobre o Uso de Drogas Psicotrópicas no Brasil aponta para uso na vida de álcool em 66,8\% para a região Nordeste do país e $13,8 \%$ para a dependência da bebida.

O uso de álcool entre adolescentes é um tema controverso, pois discorre sobre a interdependência de diversos contextos. Apesar da proibiçáo da venda de bebidas alcoólicas para menores de 18 anos, conforme a lei n. 9.294 de 1996, o consumo de álcool pelos jovens ainda é uma prática comum.

Tabela 3. Resultado dos artigos encontrados que abordam o tema na região Nordeste do Brasil.

\begin{tabular}{|c|c|c|c|c|c|c|}
\hline Revista & Ano & Título & Autores & Objetivos & Método & $\begin{array}{l}\text { Síntese dos } \\
\text { resultados }\end{array}$ \\
\hline $\begin{array}{c}\text { Caderno } \\
\text { de Saúde } \\
\text { Pública - Rio } \\
\text { de Janeiro }\end{array}$ & 2010 & $\begin{array}{l}\text { Consumo de } \\
\text { álcool entre } \\
\text { estudantes } \\
\text { de escolas } \\
\text { públicas } \\
\text { da região } \\
\text { metropolitana } \\
\text { do Recife, } \\
\text { Pernambuco, } \\
\text { Brasil }\end{array}$ & $\begin{array}{l}\text { Gomes, } \\
\text { Alvese } \\
\text { Nascimento }\end{array}$ & $\begin{array}{l}\text { Traçar um perfil } \\
\text { dos estudantes do } \\
\text { ensino médio em } \\
\text { relação ao consumo } \\
\text { de bebida alcoólica } \\
\text { e às circunstâncias } \\
\text { e consequências do } \\
\text { comportamento de } \\
\text { beber. }\end{array}$ & $\begin{array}{l}\text { Delineamento } \\
\text { de um estudo } \\
\text { epidemiológico } \\
\text { transversal }\end{array}$ & $\begin{array}{l}\text { Amostra de } \\
1.878 \text { estudantes: } \\
30,5 \% \text { já } \\
\text { beberam até a } \\
\text { embriaguez em } \\
\text { algum momento } \\
\text { da vida; } 14,5 \% \\
\text { relataram } \\
\text { consequências } \\
\text { negativas ao } \\
\text { beber como } \\
\text { ressaca, ficar } \\
\text { doente, ter } \\
\text { problemas com a } \\
\text { família, amigos, } \\
\text { faltar à escola ou } \\
\text { envolver-se em } \\
\text { brigas. }\end{array}$ \\
\hline
\end{tabular}


O Estatuto da Criança e do Adolescente estabelece que é proibida a venda de bebidas alcoólicas a crianças ou adolescentes, e produtos/substâncias cujos componentes possam causar dependência física ou psíquica, ainda que por utilização indevida. A legislação brasileira tolera a ingestão de bebidas alcoólicas desde que o indivíduo seja maior de 18 anos (PINSKY; BESSA, 2004).

Gomes, Alves e Nascimento (2010) apontam que o conhecimento do consumo de álcool na região metropolitana do Recife, poderá servir de subsídio para as Gerências de Educação, por intermédio da Secretaria de Educação e Cultura do estado de Pernambuco, para desenvolverem estratégias preventivas que envolvam intervençóes comunitárias mediante políticas públicas, a fim de evitar que problemas decorrentes da exposição precoce de adolescentes ao álcool continuem acontecendo.

A Tabela 4 refere à pesquisa realizada em Belém, PA, e traz dados sobre o uso de tabaco por adolescentes, estudantes do ensino médio.

Segundo Galduróz et al. (2004), no V Levantamento Nacional sobre Consumo de Drogas Psicotrópicas entre estudantes, em 27 capitais brasileiras, a prevalência encontrada para o uso de tabaco para a cidade de Belém foi $23,7 \%$ para uso na vida, $16,15 \%$ para uso no ano, $10,5 \%$ para uso no mês, 3,5\% para uso frequentemente e 2,2\% para uso pesado. O dado apresentado na Tabela 4 se mostrou distinto dos dados do último Levantamento Nacional sobre o Uso de Drogas Psicotrópicas.

A nicotina, na adolescência, é a droga que mais captura usuários experimentais, isso faz com que a pessoa fique logo dependente da nicotina e a abstinência passa a ser insuportável, com os sintomas de fissura, irritabilidade, agitação e ansiedade, dificuldades de concentração, sensação de incapacidade de lidar com o estresse, sudorese, tontura, insônia e cefaleia (PINSKY; BESSA, 2004).
Diversos estudos já demonstraram que é na adolescência que se encontra o grupo de maior risco para a iniciação ao tabagismo. Dessa maneira, considera-se que é nos anos de transição entre o ensino médio e superior que o jovem inicia, desenvolve e consolida seu comportamento tabagista (PINTO; RIBEIRO, 2007).

Para Pinsky e Bessa (2004), os fatores que levam $o$ adolescente ao tabagismo são, na maioria das vezes, a pressão exercida pelos amigos, o papel da mídia e das companhias tabagistas. Pesquisas mostram que três em cada quatro fumantes desejam ou já tentaram parar de fumar, sendo que menos da metade teve êxito.

A questão das drogas é uma preocupação mundial em função de sua alta frequência e dos prejuízos sociais, psíquicos e biológicos. Nessa faixa etária, há rápido desenvolvimento biopsicossocial e a ocorrência de problemas relacionados ao uso de drogas pode influenciar por toda a vida (SILVA et al., 2006). Quando um adolescente inicia o uso de drogas com pouca idade, tem maior risco de prejuízos psíquico, físico e social do que outro com maior idade (JINEZ; SOUZA; PILLON, 2009).

O uso e abuso de drogas, lícitas ou ilícitas, representam um grave problema de saúde pública e coletiva por produzir enormes e indesejáveis repercussóes sociais, culturais e econômicas. Estudos realizados em várias cidades brasileiras têm buscado averiguar a prevalência do consumo de drogas entre os jovens, problema que vem ocorrendo em muitos lugares. E é uma das maiores preocupaçóes da saúde pública (SANCEVERINO; ABREU, 2004).

O levantamento de consumo de drogas entre estudantes das capitais de dez estados brasileiros, realizado pelo Centro Brasileiro de Informaçóes sobre Drogas Psicotrópicas (CEBRID), demonstrou crescimento alarmante do uso de drogas entre adolescentes escolares. A pesquisa revela aumento

Tabela 4. Resultados dos artigos encontrados que abordam o tema na região Norte do Brasil.

\begin{tabular}{|c|c|c|c|c|c|c|}
\hline Revista & Ano & Título & Autores & Objetivos & Método & $\begin{array}{l}\text { Síntese dos } \\
\text { resultados }\end{array}$ \\
\hline $\begin{array}{c}\text { Jornal } \\
\text { Brasileiro } \\
\text { de } \\
\text { Pneumologia }\end{array}$ & 2007 & $\begin{array}{l}\text { Variáveis } \\
\text { relacionadas } \\
\text { à iniciação do } \\
\text { tabagismo entre } \\
\text { estudantes do } \\
\text { ensino médio de } \\
\text { escola pública } \\
\text { e particular } \\
\text { na cidade de } \\
\text { Belém, PA }\end{array}$ & $\begin{array}{l}\text { Pinto e } \\
\text { Ribeiro }\end{array}$ & $\begin{array}{l}\text { Analisar as variáveis } \\
\text { relacionadas } \\
\text { à iniciação do } \\
\text { tabagismo entre } \\
\text { adolescentes } \\
\text { estudantes de nível } \\
\text { médio de uma escola } \\
\text { particular e outra } \\
\text { pública na cidade de } \\
\text { Belém, PA. }\end{array}$ & $\begin{array}{l}\text { Estudo } \\
\text { transversal }\end{array}$ & $\begin{array}{l}\text { Amostra de } 1.520 \\
\text { estudantes: } 44,7 \% \\
\text { já experimentaram } \\
\text { o cigarro; } 11 \% \\
\text { fazem uso habitual. } \\
\text { A variável mais } \\
\text { importante para } \\
\text { o fumo entre } \\
\text { estudantes foi a } \\
\text { curiosidade. }\end{array}$ \\
\hline
\end{tabular}


significativo de uso na vida, uso frequente (seis ou mais vezes ao mês) e uso pesado (20 vezes ou mais ao mês) de várias drogas (GALDURÓZ et al., 1997, apud DEZONTINE et al., 2007).

O ensino médio é frequentado, predominantemente, por adolescentes, época da vida em que ocorrem grandes descobertas e transformaçôes. Período em que não são aceitas recomendaçóes com bom grado, em que a maioria dos jovens busca a autonomia e atingir de imediato seus fins. Alguns desses adolescentes encontram nas drogas uma oportunidade para fugir de uma realidade adversa ou talvez, premidos pelos colegas, experimentá-las por curiosidade (SANCEVERINO; ABREU, 2004).

Atualmente, a maior parte dos pesquisadores considera que o uso de drogas por estudantes não é causado por um único fator, mas por uma combinação de vários deles, tais como os genéticos, psicológicos, familiares, socioeconômicos e culturais. Assim, entende-se que o uso e a dependência de drogas são fenômenos bastante complexos que náo podem ser reduzidos a uma faceta da dimensáo biológica, psicológica ou social (SOLDERA et al., 2004).

Dados apontam que adolescentes provenientes de famílias mais estruturadas, com bom relacionamento familiar, tendem a usar menos drogas do que aqueles que vêm de lares desestruturados. Brigas conjugais entre os pais e maus-tratos levam à instabilidade emocional do adolescente, deixando-o mais suscetível ao mundo das drogas (BAUS et al., 2002 apud DEZONTINE et al., 2007; TAVARES et al., 2004 apud DEZONTINE et al., 2007).

Uma pesquisa realizada entre estudantes do ensino médio, no México, entre 2006 e 2007, apresenta os fatores que levaram os adolescentes ao uso de drogas como a curiosidade, o enfrentamento de situaçôes desagradáveis, o prazer, os conflitos familiares, a influência dos amigos, a solidariedade, os que náo sabem os motivos e outras razóes que não foram especificadas (JINEZ; SOUZA; PILLON, 2009).

Com o aumento da escolaridade (anos de estudo), aumenta a probabilidade, em até três vezes mais, para o uso de drogas, pois, se por um lado há a formação educativa, por outro, podem estar desvinculando-se dos familiares, associando-se a grupos de amigos, condiçóes favoráveis para o envolvimento com fatores de risco como experimentar drogas (JINEZ; SOUZA; PILLON, 2009).

A disponibilidade e a presença de drogas na comunidade de convivência têm sido vistas como facilitadoras no uso de drogas por adolescentes, uma vez que o excesso de oferta naturaliza o acesso. Quando a facilidade de oferta se junta à desorganização social e aos outros elementos predisponentes no âmbito familiar e institucional, produz-se uma sintonia de fatores (SCHENKER; MINAYO, 2005).

Horta et al. (2007) apresentam dados que apontam a preocupante associação entre um menor desempenho escolar e a ocorrência de uso de drogas. $\mathrm{O}$ uso de drogas apareceu associado também à inexistência de vínculo com a escola e a maior ocorrência de reprovaçóes escolares.

Na pesquisa realizada entre estudantes do ensino médio, no México, compararam-se os estudantes que fazem uso ou náo de drogas, concluindo-se que existe relaçáo estatisticamente significativa entre essas duas variáveis. Os estudantes que usam drogas apresentam porcentagens maiores de repetência; resultados semelhantes foram encontrados em um estudo realizado no sul do Brasil (JINEZ; SOUZA; PILLON, 2009). Para alguns adolescentes que experimentam as drogas, pode ser parte do desenvolvimento da individualidade, e são classificados como experimentadores mais que consumidores, fazem uso de substâncias de maneira ocasional e não necessariamente desenvolvem a dependência; ainda, alguns adolescentes com múltiplos fatores de risco são mais suscetíveis para desenvolver problemas relacionados ao consumo de substâncias.

Para Schenker e Minayo (2005), os adolescentes que têm objetivos definidos e investem no futuro apresentam probabilidade menor de consumir drogas porque o uso interfere em seus planos. Igualmente, a elevada autoestima, os sentimentos de valor, orgulho, habilidade, respeito e satisfação com a vida podem servir de proteçáo aos jovens contra a dependência de drogas quando combinada a outros fatores protetores do seu contexto de vida.

Os mesmos autores referem que raramente os estudos sobre drogas dão realce às amizades entre os jovens como protetoras, como influências positivas, no entanto, sabe-se que grupos de amigos com objetivos e expectativas de realização na vida e movimentos que levam ao protagonismo juvenil e à solidariedade têm papel fundamental numa etapa existencial em que as influências dos pares são cruciais.

A escola é um poderoso agente de socialização da criança e do adolescente. Por juntar em seu interior a comunidade de pares e por ter fortes instrumentos de promoção da autoestima e do autodesenvolvimento em suas mãos, o ambiente escolar pode ser um fator fundamental na potencializaçáo da resiliência dos adolescentes. 


\section{Considerações finais}

Os dados do presente trabalho permitem concluir que os estudantes pesquisados apresentam alta prevalência no uso de substâncias psicoativas, sendo as mais utilizadas o álcool e o tabaco, em seguida estão os solventes e a maconha. Verificou-se também que os adolescentes apresentam contato precoce com algumas drogas, pois tratam-se de substâncias de fácil acesso e encontradas frequentemente em muitas residências.

Diversos artigos abordam que a primeira experimentação com álcool e tabaco ocorre na própria casa, oferecidos pelos familiares, fato que deve ser levado em conta nos programas preventivos. Parece importante ressaltar que, ainda que preocupados com o potencial consumo de drogas por parte dos filhos, muitos pais parecem ignorar que o primeiro contato com drogas ocorre nos lares e com o respaldo deles próprios, intencional ou inadvertidamente. Por isso os pais precisam ser envolvidos nas propostas preventivas, enfatizando a importância da prevenção do uso de drogas lícitas e não só das ilícitas.

Schenker e Minayo (2005) abordam o papel da escola, seja como agente transformador, seja como lócus propiciador do ambiente que exacerba as condições para o uso de drogas. É de conhecimento que essa instituição é hoje alvo de assédio de traficantes e repassadores de substâncias proibidas, prevendo-se o aliciamento por pares. Observam os estudiosos que há uma sintonia no caso dos pares: os adolescentes que querem começar ou aumentar o uso de drogas procuram por colegas com valores e hábitos semelhantes.

Os mesmos autores referem que a escola é o espaço privilegiado dos encontros e interaçóes entre os jovens. No entanto, mesmo no âmbito educacional, existem fatores específicos que predispóem os adolescentes ao uso de drogas, como, por exemplo, a falta de motivação para os estudos, o absenteísmo e o mau desempenho escolar, a insuficiência no aproveitamento e a falta de compromisso com o sentido da educação, a intensa vontade de ser independente combinada com o pouco interesse de investir na realizaçáo pessoal, a busca de novidade a qualquer preço e a baixa oposição a situaçóes perigosas, a rebeldia constante associada à dependência a recompensas.

O consumo de drogas é mais um sintoma do que a causa de problemas em nossa sociedade e deve ser tratado tendo em vista a complexidade e magnitude do assunto. A forma mais eficaz de minimizar o problema é o desenvolvimento de açóes preventivas específicas para cada faixa etária, tendo como objetivo a valorização da saúde e o respeito à vida.

A diminuição de riscos com o uso de drogas na prática escolar viabiliza-se por cinco modelos básicos: conhecimento científico, em que se propóe o fornecimento de informaçóes sobre drogas de modo imparcial; educação afetiva, que defende que os jovens mais estruturados e menos vulneráveis do ponto de vista psicológico são menos propensos a se engajar num uso problemático de substâncias psicoativas; oferecimento de alternativas, em que se procura propiciar aos jovens oportunidades de crescimento pessoal, excitação, desafio e alívio do tédio; educação para a saúde dirigida a uma vida saudável, com orientaçôes sobre alimentação adequada, atividades esportivas, vida sexual segura e, finalmente, propóe modificação das condições de ensino, enfatizando a importância da pré-escola e do ensino elementar como fundamentais para um bom desenvolvimento sadio do adolescente (CARLINI, 1998 apud SANCEVERINO; ABREU, 2004).

A caracterização do consumo de drogas entre escolares torna-se importante ferramenta para as políticas públicas na busca de auxílio para a prevenção e tratamento do abuso de drogas lícitas e ilícitas (SILVA et al., 2006). A escola é vista como eixo de formação no que diz respeito à instrução, cidadania e lócus de expressão de comportamentos e personalidades, bem como de formação de hábitos, caracterizando-se como espaço privilegiado para o desenvolvimento de programas preventivos e políticas públicas (HORTA et al., 2007).

A instituição escolar deve investir na formação da comunidade escolar, abordando temas como drogas e violência de forma transversal, em que professores e gestores estão profundamente comprometidos com a causa. Também é papel da escola estar atenta às situaçôes que permita identificar fatores de risco em que os estudantes possam estar inseridos para criar e implementar ações de proteção.

Cabe às instituiçôes de ensino estabelecer instrumentos que possibilitem a prática de escuta dos adolescentes e jovens que têm na escola o lugar que lhes garante o uso da palavra e lhes ensina a prática da escuta. Usar a metodologia de redes de apoio, que servem de proteção local e asseguram a construção da cultura de paz e de ambientes saudáveis, ou seja, a garantia da dignidade humana. As estratégias utilizadas em educação em saúde devem envolver o adolescente, a família e a sociedade, pois essas táticas auxiliam os adolescentes nas experiências futuras, formando seus conceitos e valores, padróes de referência. 
Espera-se que a escola invista em programas, projetos e ações na formação para a cidadania, na educaçáo integral com espaços abertos para a educação informal e aos direitos humanos, além de ampliar tempos e saberes através de diferentes percursos pedagógicos.

Investir na formação de diferentes profissionais, possibilitando uma educação permanente, voltada para a formação de múltiplos olhares, uma formação de prevenção e segurança dos estudantes e de toda a comunidade escolar.

Caberá às instituições educativas agir dentro dos limites de sua função social e contar com os demais setores, que também têm responsabilidades em tratar da prevenção às drogas.

Por fim, são necessárias políticas públicas coesas que garantam o acesso a serviços de atenção aos usuários de drogas e que ofereçam educação, treinamento e capacitação para profissionais da saúde sobre abordagens interdisciplinares. É preciso uma atuação urgente, ampliada e articulada do poder público juntamente com uma parceria efetiva da sociedade para buscar soluçóes eficazes na problemática das drogas, sendo que a prioridade é reforçar as medidas preventivas e de proteção.

Esse estudo foi realizado dentro de algumas limitaçóes, como o falta de acesso a estudos mais recentes, a dados não publicados e a outras pesquisas que poderiam ampliar o presente trabalho. Apesar disso, buscamos trazer informaçóes concisas e reais a respeito de um assunto importante e que merece, sempre, a atenção de pesquisadores e responsáveis pela saúde pública.

\section{Referências}

BARBOSA, M. T. S.; CARLINI-COTRIM, B.; SILVA FILHO, A. R. O uso de tabaco por estudantes de primeiro e segundo graus em dez capitais brasileiras: possíveis contribuiçôes da estatística multivariada para compreensão do fenômeno. Revista de Saúde Pública, Sáo Paulo, v. 23, n. 5, p. 401-409, 1989.

CAMPOS, J. A. D. B. et al. Consumo de álcool entre estudantes do ensino médio do município de Passos - MG. Ciência \& Saúde Coletiva, Rio de Janeiro, v. 16, n. 12, p. 4745-4754, 2011. http://dx.doi.org/10.1590/ S1413-81232011001300023

CARLINI, E. A. et al. II levantamento domiciliar sobre o uso de drogas psicotrópicas no Brasil. São Paulo: CEBRID, 2005.

DEZONTINE, F. R. et al. Uso de drogas entre adolescentes estudantes de escola da rede privada em São Paulo. ConScientiae Saúde, São Paulo, v. 6, n. 2, p. 323-328, 2007. Disponível em: <http://www.uninove. $\mathrm{br} / \mathrm{PDF} /$ Publicacoes/conscientiae_saude/csaude_v6n2/ conscientiaesaudev6n2.pdf\#page=115>. Acesso em: 12 jan. 2013.
DIEHL, A.; CORDEIRO, D. C.; LARANJEIRA, R. Dependência química: prevenção, tratamento e políticas públicas. Porto Alegre: Artmed, 2011.

GALDURÓZ, J. C. F. et al. V levantamento nacional sobre o consumo de drogas psicotrópicas entre estudantes de o ensino médio da rede pública de ensino nas 27 capitais brasileiras. São Paulo: CEBRID, 2004.

GOMES, B. D. M. R.; ALVES, J. G. B.; NASCIMENTO, L. C. Consumo de álcool entre estudantes de escolas públicas da Região Metropolitana do Recife, Pernambuco, Brasil. Cadernos de Saúde Pública, Rio de Janeiro, v. 26, n. 4, p. 706-712, 2010. Disponível em: <http://www. scielo.br/pdf/csp/v25n2/16.pdf>. Acesso em: 15 abr. 20013.

GUIMARĀES, J. L. Consumo de drogas psicoativas por adolescentes escolares de Assis, SP. Revista de Saúde Pública, São Paulo, v. 38, n. 1, p. 130-132, 2004. Disponível em: <http://www.scielosp.org/pdf/rsp/v38n1/18462.pdf>. Acesso em: 10 jun. 2013.

HORTA, R. L. et al. Tabaco, álcool e outras drogas entre adolescentes em Pelotas, Rio Grande do Sul, Brasil: uma perspectiva de gênero. Cadernos de Saúde Pública, Rio de Janeiro, v. 23, n. 4, p. 775-783, 2007. Disponível em: <http://www.scielo.br/pdf/\%0D/csp/v23n4/04.pdf>. Acesso em: 11 jun. 2013.

JINEZ, L. J.; SOUZA, J. R. M.; PILLON, S. C. Uso de drogas e fatores de risco entre estudantes de ensino médio. Revista Latino-Americana de Enfermagem, Ribeirão Preto, v. 17, n. 2, p. 246-252, 2009. Disponível em: <http:// www.scielo.br/pdf/rlae/v17n2/pt_17.pdf >. Acesso em: 2 set. 2012.

MARTINS, R. A. et al. Padrão de consumo de álcool entre estudantes do ensino médio de uma cidade do interior do estado de São Paulo. SMAD: Revista Eletrônica Saúde Mental Álcool e Drogas, Ribeirão Preto, v. 4, n. 1, p. 1-16, 2008. Disponível em: <http://pepsic.bvsalud.org/ scielo.php?pid=S1806-69762008000100005\&script=sci_ arttext>. Acesso em: 25 abr. 2013.

PAVANI, R. A. B. et al. Caracterização do consumo de maconha entre escolares do ensino médio de São José do Rio Preto, SP, Brasil, 2003. Revista Brasileira de Epidemiologia, São Paulo, v. 10, n. 2, p. 157-167, 2007. http://dx.doi.org/10.1590/S1415-790X2007000200004

PINSKY, I.; BESSA, M. A. Adolescência e drogas. São Paulo: Contexto, 2004.

PINTO, D. S.; RIBEIRO, S. A. Variáveis relacionadas à iniciação do tabagismo entre estudantes do ensino médio de escola pública e particular na cidade de Belém-PA. Jornal Brasileiro de Pneumologia, Brasília, v. 33, n. 5, p. 558-564, 2007. Disponível em: <http://www.scielo.br/ pdf/jbpneu/v33n5/v33n5a11.pdf>. Acesso em: 10 jun. 2013.

SANCEVERINO, S. L.; ABREU, J. L. C. Aspectos epidemiológicos do uso de drogas entre estudantes do ensino médio no município de Palhoça, 2003. Ciência \& Saúde Coletiva, Rio de Janeiro, v. 9, n. 4, p. 10471056, 2004. Disponível em: <http://www.scielo.br/ pdf/\%0D/csc/v9n4/a25v9n4.pdf>. Acesso em: 2 set. 2012. http://dx.doi.org/10.1590/S1413-81232004000400025 
SCHENKER, M.; MINAYO, M. D. S. Fatores de risco e de proteção para o uso de drogas na adolescência. Ciência \& Saúde Coletiva, Rio de Janeiro, v. 10, n. 3, p. 707-717, 2005. http://dx.doi.org/10.1590/S1413-81232005000300027

SILVA, E. D. F. et al. Prevalência do uso de drogas entre escolares do ensino médio do Município de São José do Rio Preto, São Paulo, Brasil. Cadernos de Saúde Pública, Rio de Janeiro, v. 22, n. 6, p. 1151-1158, 2006. Disponível em: <http://www.scielosp.org/scielo.php?script=sci_ arttext\&pid=S0102-311X2006000600004\&lng=en\& $\mathrm{nrm}=\mathrm{iso} \& \mathrm{t} \operatorname{lng}=\mathrm{pt}>$. Acesso em: 2 set. 2012.

SOLDERA, M. et al. Uso de drogas psicotrópicas por estudantes: prevalência e fatores sociais associados. Revista de Saúde Pública, São Paulo, v. 38, n. 2, p. 277-283, 2004. Disponível em: <http://www.scielo. br/pdf/rsp/v38n2/19789.pdf>. Acesso em: 2 set. 2012.
VIEIRA, P. C. et al. Uso de álcool, tabaco e outras drogas por adolescentes escolares em município do Sul do Brasil. Cadernos de Saúde Pública, Rio de Janeiro, v. 24, n. 11, p. 2487-2498, 2008. Disponível em: <http://www.scielo. br/pdf/csp/v24n11/04.pdf>. Acesso em: 11 jun. 2013.

ZANINI, R. R. et al. Prevalência e fatores associados ao consumo de cigarros entre estudantes de escolas estaduais do ensino médio de Santa Maria, Rio Grande do Sul, Brasil, 2002. Cadernos de Saúde Pública, Rio de Janeiro, v. 22, n. 8, p. 1619-27, 2006. Disponível em: <http:// www.scielo.br/pdf/\%0D/csp/v22n8/10.pdf>. Acesso em: 10 jun. 2013.

ZENAIDE, M. L. R.; BALDACCI, E. R. Uso de substâncias psicoativas em adolescentes de escola pública e privada da cidade de Santos. Revista Paulista de Pediatria, São Paulo, v. 24, n. 2, p. 127-34, 2006. Disponível em: <http://www.spsp.org.br/spsp_2007/revista/24-16.pdf>. Acesso em: 10 jun. 2013.

\section{Contribuição dos Autores}

Clamarta Pasuch participou na pesquisa, no levantamento dos dados e na redação do artigo. Margareth da Silva Oliveira atuou como orientadora do trabalho, colaborou no desenho do estudo, na análise dos dados e na correçấo do artigo.

\section{Notas}

${ }^{1}$ Apresentado no V Simpósio de Dependência Química - FIPAD, Bento Gonçalves-RS, Brasil. 